\title{
49. PALEOMAGNETISM OF SEDIMENTS, SITES 438 AND 440, LEG 57, DEEP SEA DRILLING PROJECT
}

\author{
James M. Hall and Diane Smeltzer, Department of Geology, Dalhousie University, \\ Halifax, Nova Scotia B3H 3J5 Canada
}

\begin{abstract}
High deposition rate sediment sequences from DSDP Sites 438 and 440 have been examined for paleomagnetic straitigraphy. At Site 440 a complete record of epochs from the Brunhes to Epoch 5 is present. In contrast, at Site 438 a hiatus has removed most of the Matuyama and Gauss epochs. At both sites specific ages for a number of depths in the sediment sequences can be suggested as a result of the paleomagnetic study.
\end{abstract}

\section{INTRODUCTION}

We performed a paleomagnetic study of 141 vertically oriented sediment subsamples from Sites 438 and 440 (Figures 1 and 2), DSDP Leg 57. Measurements were made with a Schonstedt SSM-1A spinner magnetometer. Systematic alternating-field demagnetization of all samples was carried out. Demagnetization steps were 0 , $25,50,75,100,150,200,250,300$, and 400 oersteds peak field. Occasionally high fields were used. Demagnetization was continued until a stable remanence inclination, interpreted as indicating the inclination of the geomagnetic field during or shortly after deposition, was obtained. Stable remanence inclinations were identified by visual search of the sequence of remanence inclinations resulting from partial demagnetization of a sample. A sequence of from two to six similar inclination-declination pairs was selected as representative of the stable direction of magnetization. The average of this sequence of inclinations is defined as the stable inclination, $I_{s}$, for a sample. It proved possible to obtain stable inclinations for 124 of the 141 samples $(88$ per cent). These inclinations are listed in Table 1. Of the remaining samples 5 yielded clear original polarities, 1 was too weak to measure, 7 did not give an indication even of original polarity, 3 were received in a broken state, and 2 were measured incorrectly. Most ( 72 per cent) natural remanence intensities were in the 0.3 to 3.0 $\times 10^{6} \mathrm{emu} / \mathrm{cm}^{-3}$ range and as such were readily measurable with the equipment used.

\section{RESULTS AND INTERPRETATION}

The summarized paleomagnetic data are listed in Table 1 and are illustated in Figures 1 and 2. Two features of the data are immediately obvious. First, considerable depth intervals are frequently characterized by one polarity (at the latitudes of the sites, positive inclination can safely be assumed to represent normal polarity and negative inclination, reverse polarity). Second, the distribution of data is such that a number of long intervals at each site are well represented, whereas other intervals contain none at all. The former are indicated by lines parallel to the axes in Figures 1 and 2. The gaps in the

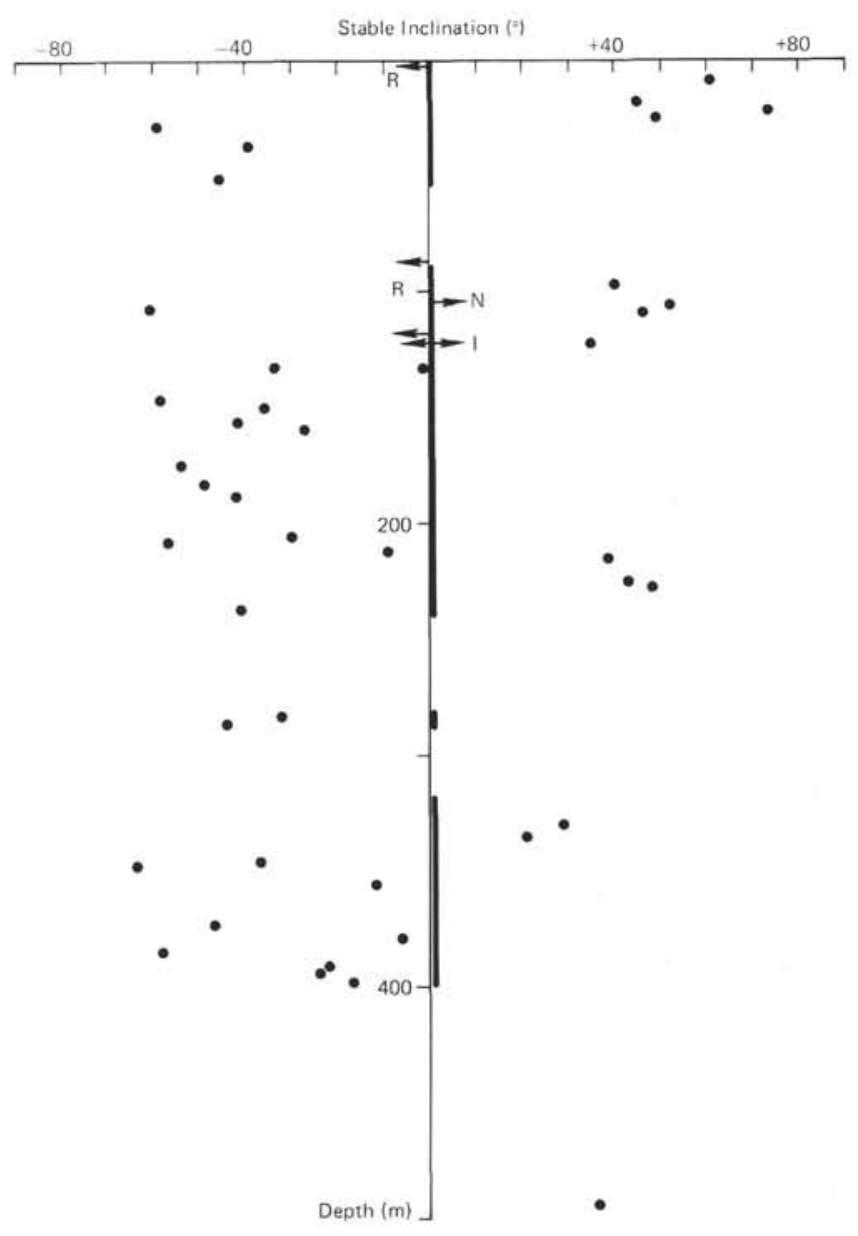

Figure 1. Site 438, Holes 438 and 438A. Stable paleomagnetic inclinations and depth.

data distributions make interpretations more difficult but not impossible.

\section{Site 440}

We chose to interpret the Site 440 record first because it appears to be straightforward. Figure 3 shoes the polarity sequence for the site in block diagram form, to- 


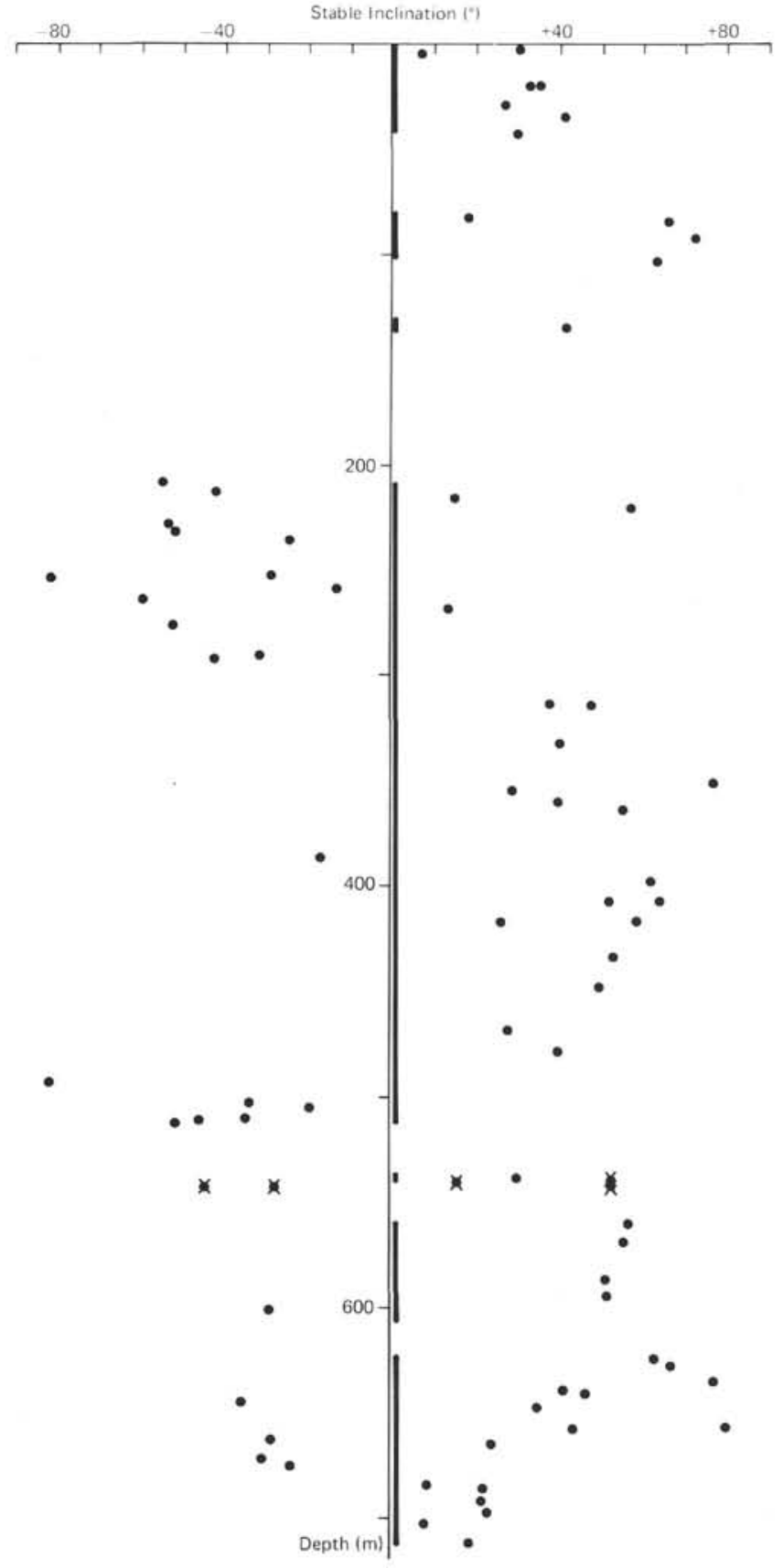

Figure 2. Site 440, Holes 440, 440A, and 440B. Stable paleomagnetic inclinations and depth.

gether with the standard sequence of McDougall (1977) plotted for a uniform sedimentation rate of $130 \mathrm{~m} / \mathrm{m}$.y. There is a good match of observed and ideal profiles, with all epochs to Epoch 5 recognizable in the Site 440 profile.

Some at least of the Jarmillo, Olduvai, mid-Gauss, and mid-Gilbert events are also present in the Site 440 profile. Small but significant mismatches between observed and ideal profiles can readily be accounted for by a combination of gaps in the data and relatively small variations in sedimentation rate. For example, according to biostratigraphic information, the upper $200 \mathrm{me}$ ters of sediment were deposited at rates approaching 230 $\mathrm{m} / \mathrm{m} . \mathrm{y}$. Thus it is difficult to resolve events in this approximately $1-\mathrm{m} . \mathrm{y}$. interval because of the data gaps and possible mismatch with the modelled results.

The value of the Site 440 profile is that it permits us to assign ages to specific depths and to ascertain the stratigraphic continuity of the sequence in conjunction with paleontological data. In particular, at the 305-meter depth the sediment age is $2.47 \mathrm{~m} . \mathrm{y}$. (Matuyama/ Gauss boundary); at 495 meters it is 3.41 m.y. (Gauss/ Gilbert boundary), and at 679 meters it is 5.44 m.y. (Gilbert/Epoch 5 boundary). These assignments agree fairly well with previously calibrated age assignments based on diatoms and other fossil groups (see Figure 4). The samples from Hole 440B, Core 43, are of special interest. They were taken from above and within a possible synsedimentary fold, two of them on the overturned limb. The sequence shows both positive and negative inclinations. The two samples with negative inclinations were taken from the overturned limb. It is probable that the magnetization predates the folding. This suggests that sediment slumped en masse from upslope after having already acquired a magnetic remanence. It is also possible that folding occurred in situ after deposition because of tectonic stresses which also caused the faulting and fracturing. However, the style of the folding suggests a synsedimentary slumping origin. Most samples below Core 440B-27 are tectonically affected by having been more highly compacted or highly fractured. There is no obvious bias in paleomagnetic parameters.

\section{Site 438}

The situation for Site 438 is much less clear than it is for Site 440 . The polarity block diagram shows dominantly reverse polarity (including the shallowest sample, Figure 5). A hiatus representing the interval from about 1.2 to $2.2 \mathrm{~m}$.y.B.P. occurs in Hole $438 \mathrm{~A}$, based on various fossil groups. Such a hiatus certainly presents complications in interpreting the polarity sequence. The estimate of the time duration of the hiatus, with part of the lower Pleistocene and upper Pliocene missing, still allows no obvious match with the ideal scale. The best model that can be suggested is that most of the lower part of the Matuyama reversed, and most of the upper Gauss normal polarity epochs may be missing. This implies that the dominantly reverse polarity sequence between 125 meters and $400+$ meters represents the Gilbert Epoch. The identification may be satisfactory, since although a high Gilbert age sedimentation rate of at least $135 \mathrm{~m} / \mathrm{m} . \mathrm{y}$. is required, this is not much higher than the rate of about $110 \mathrm{~m} / \mathrm{m}$.y. obtained from paleontologic dating (see Site 438 chapter, this volume, Pt. 1). This model implies an age of 3.41 m.y. at 125 -meter depth, of $3.82 \mathrm{~m} . y$. at 212 meters, and possibly of 4.57 m.y. at 340 meters.

\section{CONCLUSIONS}

The paleomagnetic stratigraphy established for Sites 438 and 440 agrees reasonably well with the age assignments made on the basis of daitoms, radiolarians, and calcareous nannofossils. Barron (this volume) has combined various age-calibrated (paleomagnetically) fossil 
TABLE 1

Paleomagnetism of Sediment Samples, Sites 438 and 440: Summary of Data

\begin{tabular}{cccccc}
\hline Sample & $\begin{array}{c}\text { Sub-bottom } \\
\text { Depth } \\
(\mathrm{m})\end{array}$ & $J_{O}$ & $I_{O}$ & $I_{S}$ & $\begin{array}{c}\text { Demagnetization Steps } \\
\text { Used to Obtain } I_{S}\end{array}$ \\
\hline
\end{tabular}

Site 438

Hole 438

$1-2,40-42$
$1-3,91-93$
$2-4,53-55$
$2-4,58-60$
$3-4,81-83$
$3-6,100-102$
$10-5,97-99$
$11-5,25-27$
$12-4,71-73$
$12-5,61-62$

Hole 438A

$2-2,116-8$

$2-2,133-5$

2-4, 119-20

$3-3,80-82$

$3-5,79-81$

4-6, $118-120$

$6-1,78-80$

6-2, 60-62

$7-3,60-61$

$7-4,46-48$

$7-5,53-55$

$8-5,86-88$

$8-6,85-87$

$10-3,23-25$

$10-4,67-69$

$11-2,94-96$

$11-4,42-44$

13-2, 56-58

13-3, 70-72

14-2, 40-42

14-4, 90-92

$16-3,139-141$

$16-5,72-74$

17-1, 81-83

$17-3,56-58$

$18-3,106-108$

$18-4,32-34$

19-5, 80-82

$21-1,12-14$

24-4, 84-86

24-6, 65-67

29-3, 46-48

29-5, 46-48

30-1, 100-102

$31-1,50-52$

$31-3,38-40$

$32-2,84-86$

$33-5,59-60$

$34-1,30-32$

$34-5,50-52$

$35-3,36-38$

$35-6,112-114$

36- $2,102-104$

$36-5,87-89$

46-3, 30-31

1.91
3.92
9.04

9.09
19.82
23.01
87.98
96.76
104.22
106.63

26.0
12.0
-
3.4
0.98
2.92
0.28
0.01
0.22
0.69

$\begin{array}{cc}+70 & R \\ +47 & +48 \pm 9 \\ - & - \\ & \\ +59 & +61 \pm 2 \\ +51 & +45 \pm 7 \\ +58 & +73 \pm 2 \\ -15 & \mathrm{R} \\ - & +40 \pm 6 \\ +36 & \mathrm{~N} ? \\ +46 & +52 \pm 6\end{array}$

-
$3(300-400)$
-
$5(125-400)$
$4(100-250)$
$3(75-150)$
-
$3(50-100)$
-
$3(50+100)$

25.67

25.84

28.69

$\begin{array}{ll}0.13 & - \\ 3.05 & + \\ 0.21 & +\end{array}$

36.31

39.30

50.69

107.29

108.61

119.60

120.97

122.54

132.37

133.86

147.74

148.68

156.45

158.93

175.07

176.71

184.41

187.91

205.90

208.23

211.82

214.57

224.57

225.33

236.81

249.13

282.85

285.66

328.47

331.47

335.51

344.51

347.39

355.85

369.59

372.81

379.01

385.37

390.63

394.03

398.38

491.80 $\begin{array}{ll}4.41 & +02 \\ 0.73 & +64\end{array}$

$0.48+64$

$\begin{array}{ll}0.48 & -53 \\ 0.32 & -52\end{array}$

$0.53+36+46 \pm 7$

$\begin{array}{lll}0.15 & -09 & R\end{array}$

$\begin{array}{lll}0.34 & +27 \quad 1\end{array}$

$0.23-15+35 \pm 11$

$\begin{array}{lll}0.58 & -30 & -33 \pm 5\end{array}$

$0.55+22-01 \pm 4$

$\begin{array}{lll}0.18 & -50 & -58 \pm 3\end{array}$

$2.17 \quad-36 \quad-43 \pm 1$

$\begin{array}{lll}0.28 & -06 & -42 \pm 13\end{array}$

$\begin{array}{lll}0.33 & -11 & -27 \pm 10\end{array}$

$\begin{array}{lll}0.55 & -45 & -54 \pm 0\end{array}$

$0.38+34$

$0.51 \quad-30 \quad-49 \pm 1$

$\begin{array}{lll}1.30 & -44 & -42 \pm 7\end{array}$

$\begin{array}{lll}0.39 & -09 & -30 \pm 9\end{array}$

$\begin{array}{lll}0.52 & -34 & -57 \pm 9\end{array}$

$\begin{array}{lll}0.39 & -39 & -09 \pm 3\end{array}$

$0.64+37+39 \pm 1$

$0.97+66+43 \pm 6$

$0.89+38+48 \pm 8$

$0.21 \quad-09 \quad-41 \pm 4$

$\begin{array}{lll}1.99 & -52 & -\end{array}$

$\begin{array}{lll}0.48 & -12 & -32 \pm 0\end{array}$

$0.51-\quad-44 \pm 13$

$0.12+09+29 \pm 1$

$0.76-04$

$0.31+27$

$0.17 \quad-06 \quad-37 \pm 11$

$\begin{array}{lll}0.27 & -59 & -64 \pm 8\end{array}$

$\begin{array}{lll}0.34 & +23 & -12 \pm 6\end{array}$

$1.27+16$

$0.61-14$

$0.32-\quad-58 \pm 7$

$\begin{array}{lll}0.28 & -09 & -22 \pm 8\end{array}$

$0.14-\quad-24 \pm 4$

$\begin{array}{lll}0.25 & -05 & -17 \pm 0\end{array}$

$0.52+38+37 \pm 3$
$3(50+100)$

$4(150-300)$

6(150-400)

$3(75-150)$

$4(50-150)$

$5(75-250)$

$5(100-300)$

$2(125,150)$

$3(50-100)$

$6(50-250)$

$4(150-300)$

$4(75-200)$

$3(150-250)$

$4(100-250)$

$4(150-300)$

$5(100-300)$

$2(75,100)$

$2(50,75)$

5(150-350)

$2(75,100)$

$3(150-250)$

$3(75-150)$

3(75-150)

$2(150,200)$

$3(150-250)$

$2(75,100)$

$3(100-200)$

$2(50,75)$

$3(75-150)$

$2(50,75)$

$3(75-150)$
No stable value

Returns to $\mathrm{N}$ after 150 but with irregular $\mathrm{J}$ variation

No stable value

Good R but no clear $I_{S}$ value

Probably near horizontal

? Inverted

Site 440

Poorly defined

Data lost through error in the measurement procedure

Definite R

May be trying to reverse

Negative to positive $I$, no stable value

Probably shallow

No stable value

$3(75-150)$ $4(200-350)$ 
TABLE 1 - Continued

\begin{tabular}{|c|c|c|c|c|c|c|}
\hline $\begin{array}{c}\text { Sample } \\
\text { (Interval in } \mathrm{cm} \text { ) }\end{array}$ & $\begin{array}{l}\text { Sub-bottom } \\
\text { Depth } \\
\text { (m) }\end{array}$ & $J_{o}$ & $I_{O}$ & $I_{s}$ & $\begin{array}{l}\text { Demagnetization Steps } \\
\text { Used to Obtain } I_{S}\end{array}$ & Comments \\
\hline
\end{tabular}

Site 440 (Cont.)

Hole 440 (Cont.)

$1-3,120-122$

$2-3,25-27$

3-3, 20-22

3-3, 101-102

$43,95-97$

$4-6,126-128$

$5-6,10-12$

4.21
9.76
19.21
20.01
29.46
34.27
42.61

$\begin{array}{ccc}4.62 & +07 & +07 \pm 3 \\ - & - & - \\ 1.11 & {[+51]} & {[+35 \pm 6]} \\ 1.73 & +25 & +33 \pm 7 \\ 2.97 & +20 & +27 \pm 8 \\ 4.17 & +32 & +41 \pm 5 \\ 29.54 & +33 & +30 \pm 2\end{array}$

$5(150-350)$
$\quad-$
$5(75-250)$
$5(75-250)$
$5(100-300)$
$6(75-300)$
$4(200-350)$

Hole 440A

$$
\begin{aligned}
& 2-1,90-92 \\
& 2-6,28-30 \\
& 3-1,72-74 \\
& 4-1,67-69
\end{aligned}
$$

$7-4,13-15$

83.43

90.29

92.73

102.18

\begin{tabular}{|c|c|c|c|c|c|}
\hline $8-3,75-77$ & 209.76 & 14.15 & -44 & $-55 \pm 1$ & $4(75-200)$ \\
\hline $8-5,86-88$ & 212.87 & 4.81 & -38 & $-42 \pm 2$ & $4(75-200)$ \\
\hline $9-1,35-37$ & 215.86 & 0.92 & +17 & $+15 \pm 6$ & $3(100-200)$ \\
\hline $9-3,70-72$ & 219.21 & 2.65 & +43 & $+57 \pm 5$ & $3(150-250)$ \\
\hline $10-3,101-102$ & 229.01 & 0.30 & -54 & $-53 \pm 2$ & $3(50-100)$ \\
\hline $10-5,70-72$ & 231.71 & 1.59 & -19 & $-52 \pm 1$ & $2(75,100)$ \\
\hline $11-1,44-46$ & 234.95 & 3.77 & -14 & $-25 \pm 2$ & $4(100-250)$ \\
\hline $11-5,100-102$ & 241.51 & 3.89 & - & - & - \\
\hline $12-5,31-32$ & 250.31 & 0.98 & -65 & $-29 \pm 17$ & $4(100-250)$ \\
\hline $13-1,27-29$ & 253.78 & 28.73 & -81 & $-81 \pm 1$ & $4(500-1000)$ \\
\hline $13-4,47-49$ & 258.48 & 1.02 & -23 & $-13 \pm 0$ & $2(150,200)$ \\
\hline $14-2,36-38$ & 264.87 & 0.86 & -36 & $-59 \pm 15$ & $3(150-250)$ \\
\hline $144,91-93$ & 268.42 & 1.02 & +41 & $+14 \pm 9$ & $4(150-300)$ \\
\hline $15-3,70-72$ & 276.21 & 1.11 & -61 & $-52 \pm 11$ & $4(150-300)$ \\
\hline $16-7,31-33$ & 291.32 & 0.67 & -13 & $-31 \pm 3$ & $4(100-250)$ \\
\hline $17-2,30-32$ & 293.31 & 8.15 & +07 & $-42 \pm 2$ & $3(100-200)$ \\
\hline $19-4,63-65$ & 315.64 & 1.43 & +37 & $+38 \pm 3$ & $4(150-300)$ \\
\hline $19-4,82-84$ & 315.83 & 1.58 & +34 & $+48 \pm 3$ & $6(150-400)$ \\
\hline $21-3,60-62$ & 333.11 & 0.68 & +38 & $+40 \pm 7$ & $3(150-250)$ \\
\hline $23-2,119-121$ & 352.20 & 0.67 & +51 & $+77 \pm 9$ & $4(140-300)$ \\
\hline $23-5,13-15$ & 354.64 & 0.28 & 00 & $+29 \pm 6$ & $4(75-200)$ \\
\hline $243,46-48$ & 361.47 & 1.24 & +36 & $+40 \pm 7$ & $4(150-300)$ \\
\hline $24-4,147-149$ & 363.98 & 1.00 & +56 & $+56 \pm 1$ & $2(150,200)$ \\
\hline $27-1,82-84$ & 387.33 & 1.84 & +07 & - & - \\
\hline $27,02-04$ & 507.05 & 1.18 & -11 & $-17 \pm 7$ & $2(75,100)$ \\
\hline $28-1,80-82$ & 396.81 & 2.47 & +65 & $+62 \pm 1$ & $3(100-200)$ \\
\hline $29-1,116-118$ & 406.67 & 0.98 & +70 & $+64 \pm 1$ & $4(75-200)$ \\
\hline $29-2,98-100$ & 407.99 & 1.17 & +48 & $+52+1$ & $3(150-250)$ \\
\hline $30-1,60-62$ & 415.61 & 1.28 & +54 & $+59 \pm 3$ & $4(100-250)$ \\
\hline $30-2,94-96$ & 417.45 & 0.74 & +27 & $+26 \pm 3$ & $5(100-300)$ \\
\hline $32-1,24-27$ & 434.26 & 0.34 & +28 & $+53 \pm 1$ & $3(150-250)$ \\
\hline $32-4,45-47$ & 438.96 & - & - & - & - \\
\hline $33-3,105-107$ & 447.56 & 1.98 & +45 & $+50 \pm 4$ & $5(200-400)$ \\
\hline $35-4,92-94$ & 467.93 & 0.62 & +18 & $+28 \pm 3$ & $4(75-200)$ \\
\hline $36-4,66-68$ & 477.17 & 0.41 & +55 & $+40 \pm 2$ & $3(50-100)$ \\
\hline $38-2,95-97$ & 493.96 & - & - & - & - \\
\hline $38-2,99-101$ & 493.50 & 0.36 & -70 & $-81 \pm 2$ & $4(75-200)$ \\
\hline $39-3,58-60$ & 504.09 & 0.19 & - & $-34 \pm 4$ & $3(200-300)$ \\
\hline $39-4,48-50$ & 505.49 & 0.55 & -02 & $-20 \pm 5$ & $3(150-250)$ \\
\hline $40-1,61-63$ & 510.62 & 0.34 & -05 & $-46 \pm 2$ & $3(200-300)$ \\
\hline $40-1,67-69$ & 510.68 & 0.31 & +12 & $-35 \pm 10$ & $5(150-350)$ \\
\hline $41-2,93-95$ & 512.44 & 0.42 & -44 & $-52 \pm 1$ & $5(100-300)$ \\
\hline $43-1,28-30$ & 538.79 & 0.71 & +30 & $+30 \pm 3$ & $3(200-300)$ \\
\hline $43-1,146-148$ & 539.47 & 0.52 & +56 & $+53 \pm 4$ & $4(75-200)$ \\
\hline $43-2,29-31$ & 540.30 & 0.45 & +22 & $+16 \pm 0$ & $2(100,150)$ \\
\hline $43-3,41-43$ & 541.92 & 0.22 & +47 & $+53 \pm 2$ & $4(75-200)$ \\
\hline $43-3,62-65$ & 542.13 & 0.38 & -04 & $-28 \pm 0$ & $2(150,200)$ \\
\hline $43-3,80-82$ & 542.31 & 0.44 & -20 & $-45 \pm 2$ & $4(100-250)$ \\
\hline
\end{tabular}

134.64

$\begin{array}{lll}1.10 & +31 & +66 \pm 3 \\ 2.06 & +62 & +72 \pm 2 \\ 2.09 & +17 & +18 \pm 2 \\ 3.95 & +58 & +63 \pm 3 \\ 1.40 & +50 & +41 \pm 6\end{array}$

Hole $440 B$
Too weak to measure

Sample loose in holder

$3(100-200)$

$4(100-250)$

$3(75-150)$

$4(100-250)$

$5(75-250)$

Orientation error during measurement

? Drilling remanence present

Changes sense of inclination twice

fractured, faulted, slightly titled, bedding inclined $25^{\circ}-30^{\circ}$, intensely burrow-mottled

Sample received in broken state

Sample received in broken state

Samples from synsedimentary fold: beds both overturned and right side up 
TABLE 1 - Continued

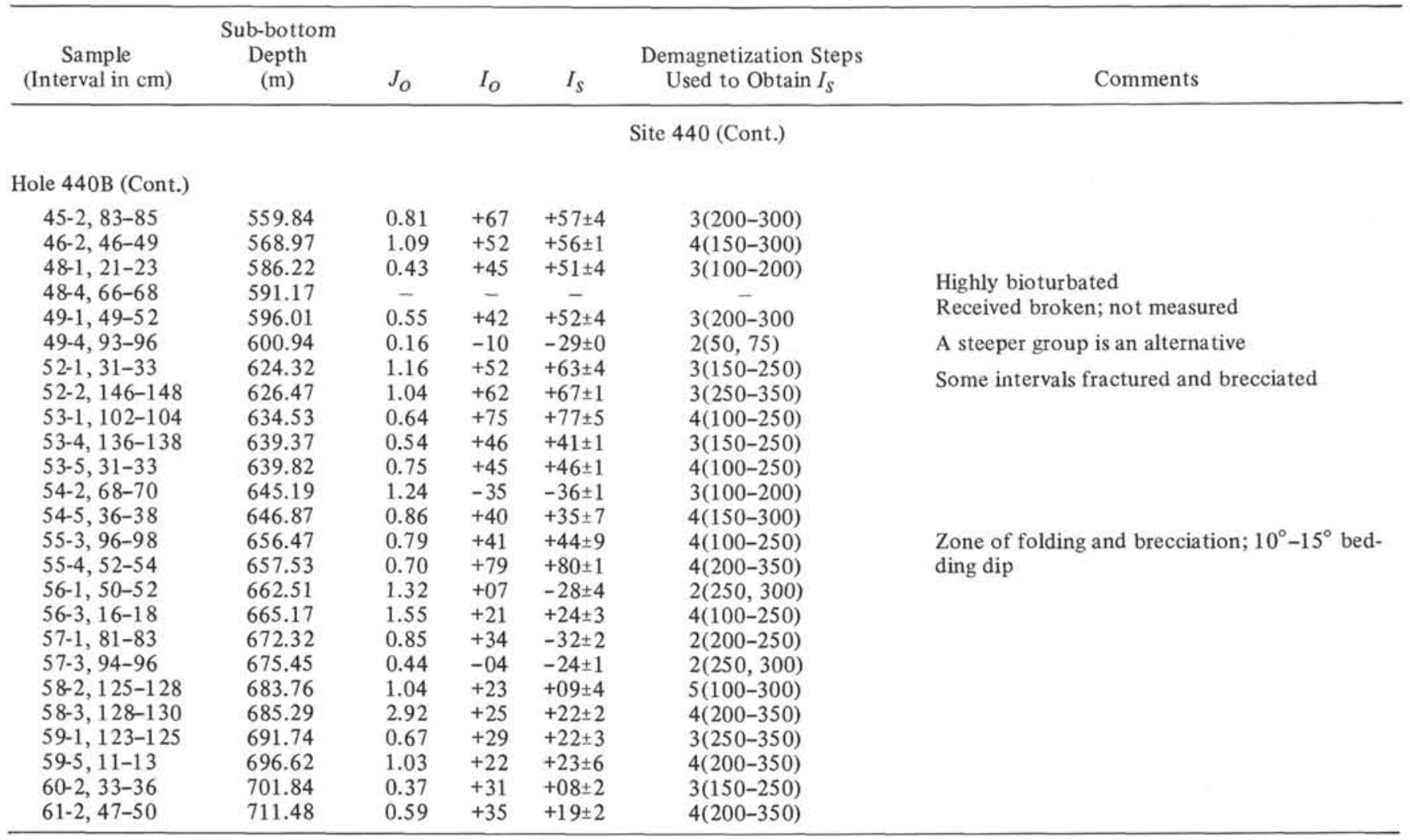

Note: $J_{O}$ is natural remanence intensity in emu/cm3 $3 \times 10^{6} ; I_{O}$ is inclination of undemagnetized remanence $\left({ }^{\circ}\right)$; and $I_{S}$ is stable inclination $($ defined in text) \pm 1 standard deviation.

datums, especially those of diatoms (Burkle and Opdyke, 1977; Koizumi, 1977), in order to add precision to age assignments in a subzonal scheme for high latitudes (Figure 2). The boundaries of various magnetic polarity epochs and events determined in this study are shown plotted on sedimentation rate curves with paleontologic datums for both sites in Figures 4 and 6 . The scheme for Site 440 shows good agreement except for the position of the Matuyama/Gauss boundary, which would appear to be placed about 50 meters too shallow in the hole relative to biostratigraphic markers of roughly equivalent age. However, on the basis of the samples it seems to be a good boundary, which suggests that the paleontologic datum may have been incorrectly selected or calibrated.

The boundaries of magnetic polarity zones outlined for Site 438 are somewhat less certain because of gaps in sample coverage and because of a hiatus which represents upper Pliocene-lower Pleistocene time. Two alternatives are provided in Figure 6. The second alternative allows a good fit between biostratigraphic and paleomagnetic zonal schemes (see Figure 7).

Paleomagnetic studies are very useful in high sedimentation rate active margin settings, even where tectonic deformation has affected the sediment. Measurable intensities and stable magnetic inclinations may be obtained from hemipelagic sediment that has been deposited at rates in excess of $120 \mathrm{~m} / \mathrm{m}$.y. or been severely fractured, veined, and overconsolidated. However, sampling is limited by how well the fractures hold together during drilling and subsequent handling, and paleomagnetic stratigraphy is limited by the recovery and sampling interval. Therefore it was not possible to study the sequence at Site 441 , for example. Even so, the technique is useful in tectonically disturbed sections as an independent control on biostratigraphic zonations, for possible calibration of paleontologic datums and ash layer chronologies, for detecting possible slump zones and folds, and for the continuity of stratigraphic sequences.

\section{ACKNOWLEDGMENTS}

We would like to acknowledge Dr. Michael Arthur for suggesting the study of paleomagnetic zonation in an oceanic area of high sedimentation rate and for review of and additions to this report. We wish to thank the Deep Sea Drilling Project for the supply of samples and for financial support for the measurement program.

\section{REFERENCES}

Burkle, L.H., and Opdyke, N. 1977. Late Neogene diatom correlations in the circum-Pacific. Proceedings of the First International Congress on Pacific Neogene Stratigraphy: Tokyo (Kaiyo Shuppan), pp. 225-284.

Gartner, S., 1977. Calcareous nannofossil biostratigraphy and revised zonation of the Pleistocene. Mar. Micropaleont., 2, $1-25$. 
Koizumi, 1., 1977. Diatom biostratigraphy in North Pacific region. Proceedings of the First International Congress on Pacific Neogene Stratigraphy: Tokyo (Kaiyo Shuppan), pp. 235-253.
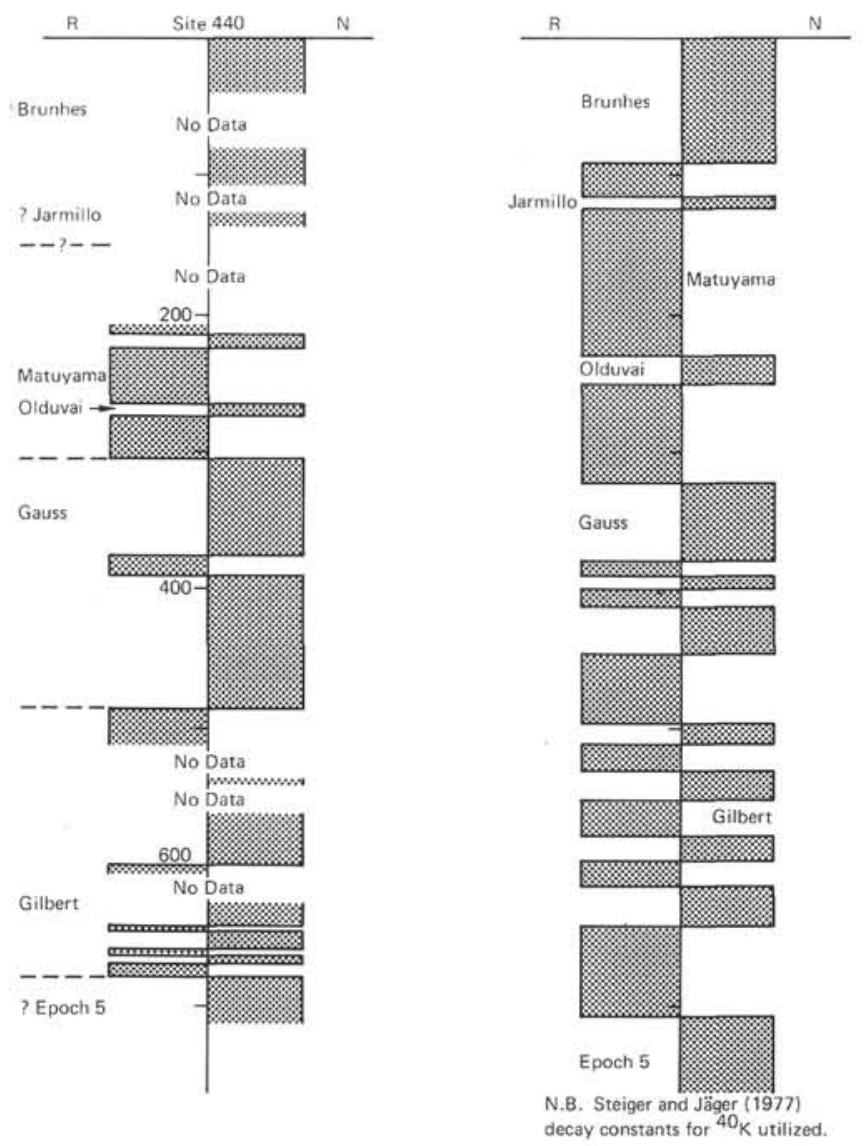

Figure 3. Site 440, Holes 440, 440A, and 440B. Suggested correlation of polarity sequence with standard sequences (McDougall, 1977).
McDougall, 1., 1977. The present status of the geomagnetic polarity time scale. In McElhinny, M. W. (Ed.), The Earth; Its Origin, Structure and Evolution: London (Academic Press).

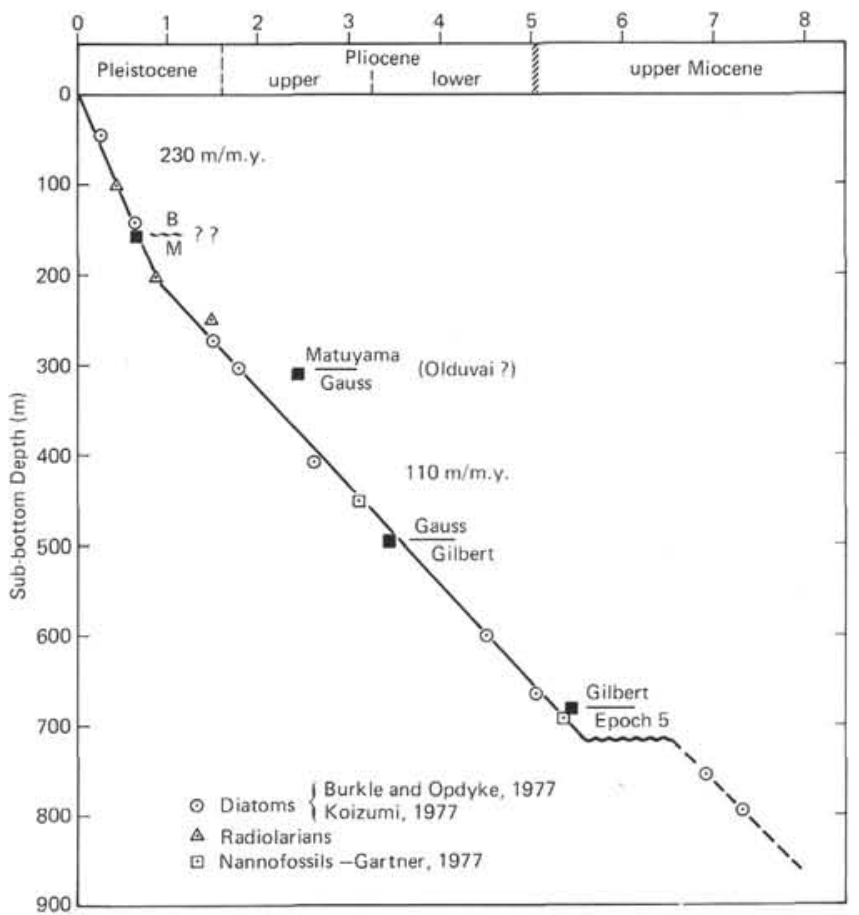

Figure 4. An age versus depth curve for Site 440 showing the correlation between specific paleomagnetic events and the biostratigraphy. 


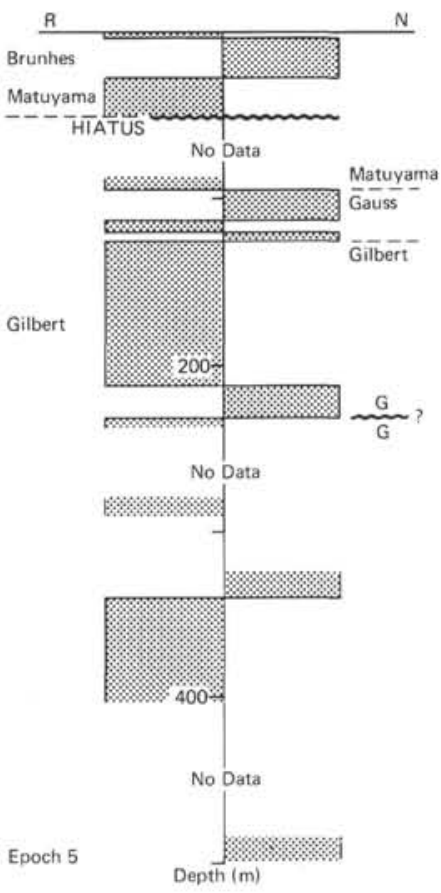

Figure 5. Site 438, Holes 438, 438A. Suggested correlation of polarity sequence with standard sequences (McDougall, 1977).

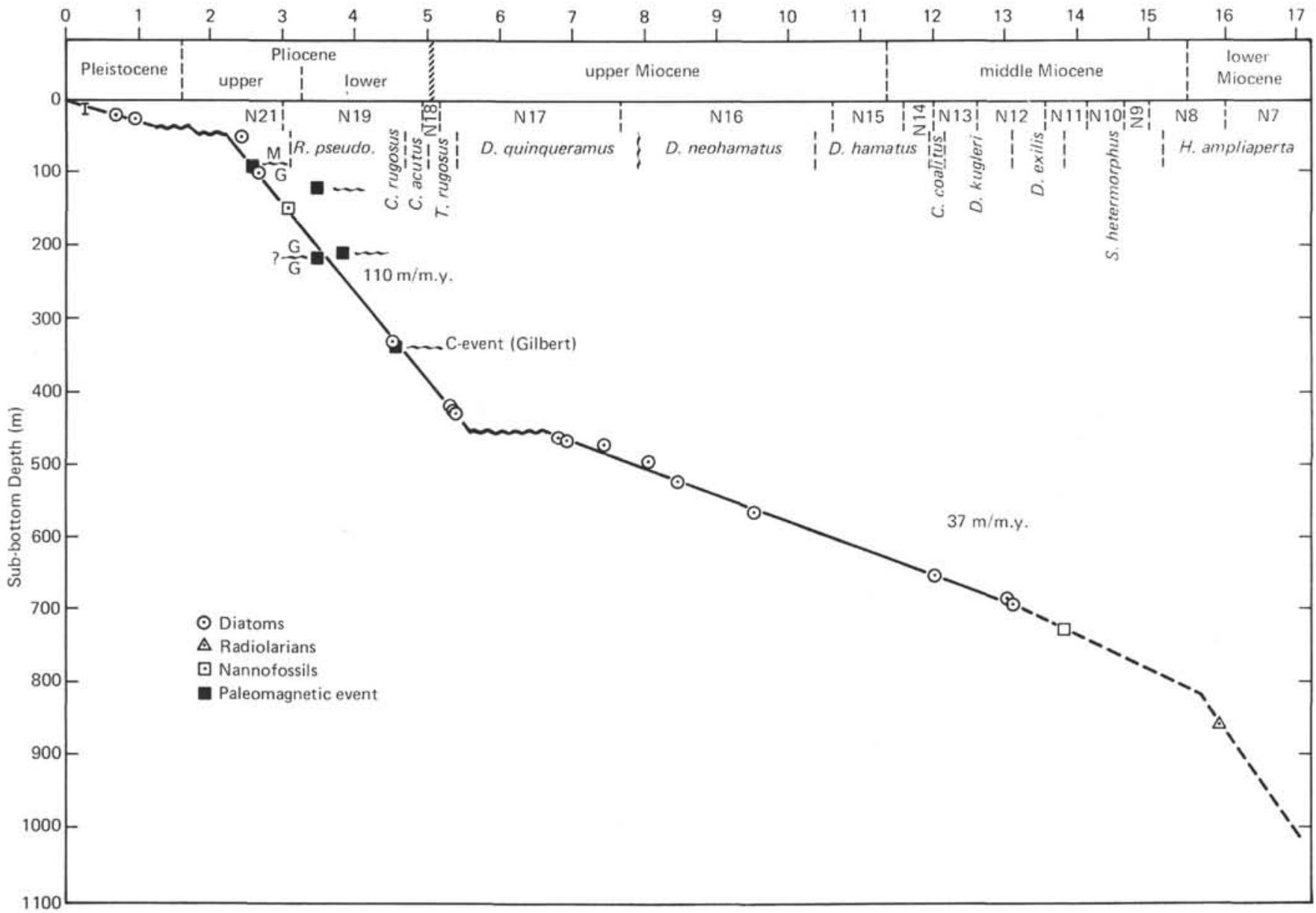

Figure 6. An age versus depth curve for Site 438 showing the correlation between specific paleomagnetic events and the biostratigraphy. 


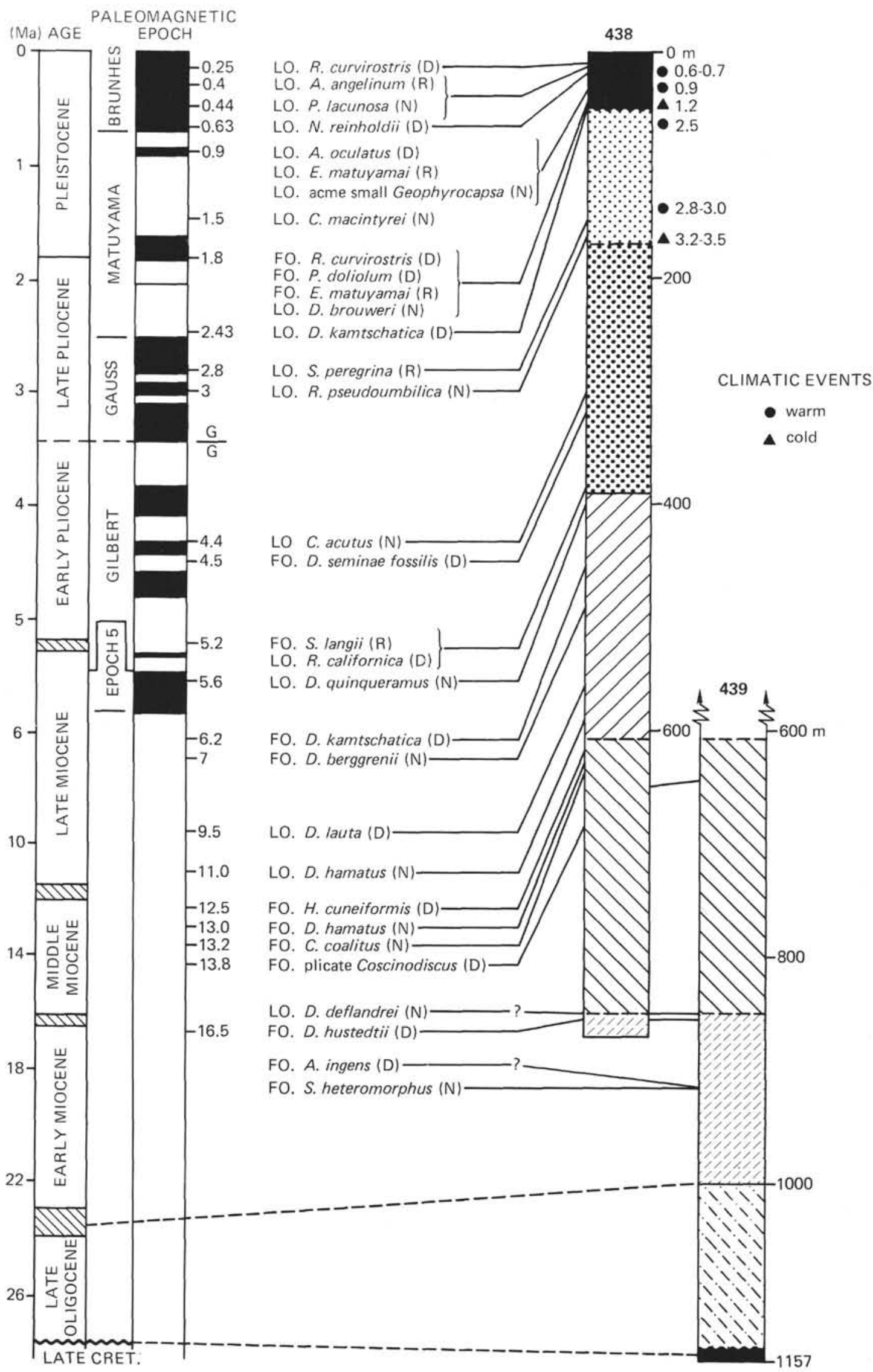

Figure 7. Summary of the paleomagnetic stratigraphy and biostratigraphy at Site 438. 